\title{
Involvement Load Hypothesis: Word Meaning Retention across Oral and Written Task Types
}

\author{
Javad Ahmadi Fatalaki \\ Department of English Language and Literature, Faculty of Persian Literature and Foreign Languages, \\ Allameh Tabataba'i University, Tehran, Iran \\ Tel: 0989195336974 \\ E-mail address: j.ahmadi921@atu.ac.ir , Ahmady.Fatalaky@gmail.com
}

\begin{abstract}
Involvement Load Hypothesis for the first time has been proposed by Laufer and Hulstijn (2001). Based on their theory, second language vocabulary learning, consists of three basic components: need, search, and evaluation. Those Tasks which induce a higher involvement load are more effective than those with lower involvement. The important question is that which modality has the higher effect on task involvement load? In order to answer this question, this study aims at discussing the effect of modality-based activities, that is, Listening and Reading, on task-induced involvement on vocabulary learning of Iranian Intermediate EFL Learners. To do so, 36 EFL learners from three branches of an English institute were selected. In order to have a more homogeneous sample population Nelson's (1977) placement test was administered. Based on their scores, students were classified into two high and low proficient groups. Then participants were then randomly assigned to two groups: The first group receives reading input and the second group receives listening input. The comparison of the students' performance in the immediate posttests revealed that the students who received reading task were more successful in the retention of newly-learned vocabularies and there wasn't significance difference between groups after the delayed posttest.
\end{abstract}

Keywords: Involvement Load Hypothesis; Task-Induced Involvement; Listening and Reading Modalities

\section{INTRODUCTION}

\section{1. Background}

The matter of vocabulary learning is not only a concern for learners, but also teachers of English language have trouble during the teaching of vocabulary. Therefore, for both language teachers and learners vocabulary is obviously a top priority (Schmitt, 2008). For intermediate and advanced level students, acquisition of words is necessary to have better performance in their speaking and even writing tasks. Hence, remains is the question of how to help students acquiring more words by spending less time; a problem with which many language teachers and educational policy makers are dealing.

Words can be selected when students are participating in reading, listening, speaking and even writing tasks. So, how to help students expanding their vocabulary size and strengthening the retention of vocabulary when they encounter with new words should be an important issue 
to be discussed by language teachers and policy makers. The point here is that how different modalities strengthen students' capability for retention of new vocabulary for the time being and for the long time after the instruction?

\section{2. Statement of the Problem}

Krashen (1989) stated that extensive reading is the best way of the retention of the newly seen vocabularies, but the new studies like Brown, Waring and Donkaewbua's (2008) one reveled the role of the listening in the retention of the vocabularies.

Like Krashen belief, previous researchers always focused on the role of written tasks (Reading) which is accompanied by writing tasks. There is no study which fully focuses on listening or even compares listening with reading to see whether which one is the most efficient one.

\section{3. Purpose of the study}

The present study, unlike other studies which exactly have focused on reading, aims at finding whether listening is the better input for learning new words while the study is based on Involvement Load Hypothesis (henceforth, ILH). In order to resolve this issue, the present study will compare listening with reading while the final task like other studies is base on writing tasks because writing is the easiest and the most objective way of understanding of students' word knowledge. Therefore, major role of this study is on input and its modalities, That is, listening and reading.

\section{4. Research Questions}

Are there significance differences between oral and written tasks for retention of vocabularies in the long run?

\section{5. Research Hypothesis}

Research question lends itself to be stated in a null hypothesis:

The differences between oral and written tasks do not significantly have impacts on learners' vocabulary retention.

\section{6. Limitations and Delimitations of the Study}

Several limitations are attributable to the present study like short duration of time and failure for considering students' personal ability for word retention (e.g., students 'audiovisual intelligence).

The other issue is the generalizability, that is, external validity, of the present study is not acceptable because of the following reasons:

1- Participants of the study are all females.

2- Result of the data based on the intermediate students at three institutes in Tehran.

3- It is related to the Iranian EFL learners

This project also is limited to the study of the effect of reading and listening tasks on vocabulary retention. These tasks might consist of different parts and integrate different skills.

The researcher's concern is on input modalities and there are no separated listening and reading tasks because they are merged into the writing tasks (Appendix B, C, \&D). Hence, the 
result doesn't purely show the effect of these tasks, and it just reveals the importance of the input modalities.

\section{7. Definition of the Key Terms}

\section{Involvement Load Hypothesis (ILH)}

Laufer and Hulstijn (2001) advanced the Involvement Load Hypothesis for second language vocabulary learning, in which they proposed a motivational-cognitive construct of involvement, consists of three basic components: need, search, and evaluation.

\section{Depth of Processing}

Depth of processing model was the theory which was proposed by Craik, and Lockhart (1972). They believe that retention in the long-term memory depends on how deeply information is processed during learning.

\section{Involvement Index}

Need, search, and evaluation are important factors of the Involvement Load Hypothesis. Hulstijn and Laufer (2001) offered the involvement index, which appointed numerical weights in which "absence of a factor is marked as 0 , a moderate presence of a factor as 1 , and strong presence as 2 " (p. 544).

\section{LITERATURE REVIEW}

\section{1. Levels of processing}

The concept of 'levels of processing' for the first time was mentioned by Craik and Lockhart (1972), who suggested that retention and remembering of knowledge and information depends not only on attending to information as it occurs but also on the depth of the process which they go through. They believe that deeper levels of processing contribute to more elaborate, long lasting, and stronger traces. Later, they have added that processing the sensory features of a new lexical item (e.g., orthography) occurs at a shallow level, whereas processing the semantic attributes (e.g., meaning) takes place at a rather deep level (cited in Ana MartínezFernández, 2008).

\section{2. The Involvement Load Hypothesis (need, search and evaluation)}

Laufer and Hulstijn (2001) proposed the notion of Involvement Load Hypothesis in order to cover the lack of depth of processing theory operationability.

According to the hypothesis, task-induced involvement consists of three basic factors need, search, and evaluation. The first factor (need) deals with motivational dimension of ILH. Need can be moderate (Teacher asks for identification of a word) or even it can be strong (selfimposed). The second factor (search) is cognitive dimension of the ILH. It deals with the attempt to find the meaning, translation of given words by the help of the teacher and dictionaries. The third factor (evaluation) means the assessment of the appropriate meaning of a special word in a specific context. When evaluation is the use of a new word in a given sentence it is moderate, but when the learners are asked to produce an original sentence, evaluation is strong. Because of the importance of this factor, Laufer, and Hulstijn (2001) clarified it by more explanation: 
a comparison of a given word with other words, a specific meaning of a word with its other meanings, or combining the word with other words in order to assess whether a word does or does not fit its context (p. 14).

\subsection{Listening and Reading Tasks studies}

Few studies have worked on L2 vocabulary learning through listening. Brown, Waring and Donkaewbua (2008) examined the Japanese EFL students' performance when reading accompanied by listening. They found the reading-while-listening produced the greatest gains (5 of 28 words). Little (2007) examined the value of listening and generative tasks in enhancement of L2 vocabulary acquisition. Little found listening to and retelling twelve 3-5 minute stories helped, among other learners, highly proficient Japanese EFL learners to acquire 300 target words within two weeks and resulted in retention over four weeks (cited in Afsane Ravandpour, 2009). Superiority of the reading modality has been proved by the previous studies because reading activity includes high involvement tasks over low involvement tasks. Hulstijn (1992) stated that word meaning remembrance is more efficient by reading than by providing synonyms. Paribakht and Wesche (1997) emphasized the effect of reading activities. They showed that words practiced in vocabulary-focused exercises following reading tasks resulted in better retention of vocabularies.

\section{METHOD}

\section{1. Participants}

Upon obtaining permissions from principals, researchers conducted the study on 36 intermediate students from Shoukoh, Kish, and Safir institutes. Participants of this study were female. Their ages ranged from 18 to 23 . This investigation was conducted during normal class time in about a six-week period.

\section{2. Instrumentation}

\section{2. 1. Pretest}

In order to have a more homogeneous sample population Nelson's (1977) placement test was administered. Based on their scores, students were classified in to two high and low proficient groups. Then, the students of the low proficient group were selected as the sample population of our study.

\section{2. 2. Tasks}

The tasks used in this study comprised a reading and listening activity containing the target words, accompanied by five reading comprehension questions of the reading passage, and two (immediate and delayed) posttests. Both listening and reading text were adapted from an article in a reading-comprehension book, Reading Master (Liu et al., 2002). The passage was about the suppression of emotions and the potential threats of such behavior to the mental and physical health of human beings. The text contained 331 words.

\section{2. 3. Posttest}

Two vocabulary tests (immediate and delayed posttests) were administered in this study to measure the participants' vocabulary knowledge upon their completion of the tasks and one 
week after their performing these tasks, respectively. No vocabulary pretest was given directly to the participants so as to avoid undue attention to the target words on the part of the students.

\section{2. 4. Immediate posttest}

Upon the completion of the tasks, the participants in both experiments were unexpectedly given an immediate posttest, containing a list of the ten target words (see Appendix C).

\section{2. 5. Delayed Posttest}

The participants in this study attempted an unexpected delayed posttest one week after their performing the tasks. This second vocabulary test was composed of items identical to those in the immediate posttest, yet with the order of the ten target words randomized (see Appendix D).

\section{3. Data collection Procedures}

Nelson Proficiency test let us make a more clear-cut classification based on their proficiency level. Then, the classification became easy and the target group was extracted. One week before the beginning of the class, pre-test was conducted on the target group.

After Nelson pretest which defines low proficiency and high proficiency groups, in order to compare listening with reading, participants were divided to two groups). The first group (n $=9)$ will receive reading input and the second group $(n=9)$ received listening input. The materials are the same in the both of the tasks (reading, \& listening), so the modalities of the input were different but the point is that both of them were terminated to the writing tasks (As we see in Table $1 \& 2$ ).

Table 1. Degree of components in Involvement Load hypothesis.

\begin{tabular}{|c|c|c|}
\hline Components & $\begin{array}{l}\text { Degrees of the } \\
\text { Involvement Load }\end{array}$ & Explanations \\
\hline \multirow{3}{*}{ Need } & Index 0 (None) & $\begin{array}{c}\text { The learner does not feel the need to learn the } \\
\text { word. }\end{array}$ \\
\hline & Index 1 (Moderate) & The learner is required to learn the word. \\
\hline & Index 2 (Strong) & The learner decides to learn the word. \\
\hline \multirow{3}{*}{ Search } & Index 0 (None) & $\begin{array}{l}\text { They do not need to learn the meanings or } \\
\text { forms of the word. }\end{array}$ \\
\hline & Index 1 (Moderate) & The meaning of the word is found. \\
\hline & Index 2 (Strong) & The form of the word is found. \\
\hline \multirow{3}{*}{ Evaluation } & Index 0 (None) & The word is not compared with other words. \\
\hline & Index 1 (Moderate) & $\begin{array}{l}\text { The word is compared with other words in the } \\
\text { provided context. }\end{array}$ \\
\hline & Index 2 (Strong) & $\begin{array}{l}\text { The word is compared with other words in } \\
\text { self-provided context. }\end{array}$ \\
\hline
\end{tabular}


Table 2. Tasks.

\begin{tabular}{|c|c|c|c|c|}
\hline Task & Status or target words & $\begin{array}{c}\text { Need } \\
\text { Index }\end{array}$ & $\begin{array}{c}\text { Search } \\
\text { Index }\end{array}$ & $\begin{array}{c}\text { Evaluation } \\
\text { Index }\end{array}$ \\
\hline $\begin{array}{c}\text { Listening or Reading } \\
\text { comprehension and } \\
\text { Multiple choice }\end{array}$ & $\begin{array}{c}\text { Highlighted, marginally- } \\
\text { glossed }\end{array}$ & 1 & 0 & 0 \\
\hline Gap filling & Glossed with meaning & 1 & 0 & 1 \\
\hline Composition & Without glossing & 1 & 1 & 1 \\
\hline
\end{tabular}

By assuming indexes moderate, researcher tested students' score on the multiple choice test when the index is 1 . Index 1, here means no search (because of glossing) and no evaluation (no real use of target words).Then, researcher tested students' score on gap filling test where there is no need for search because of glossing but evaluation entered because students had to evaluate and write the appropriate answer. The third task which is composition needs all ILH components (Need, Search, and evaluation).

\section{4. Data analysis}

In order to answer the research question, the following statistical analyses were used. To compute all data, mean and standard deviation of all students were calculated. Researchers compared the result of students' performance on listening and reading tasks. Then, researchers found which type of task was more beneficial in learning and retention of the target words.

\section{RESULT}

\section{1. Immediate Post Test Result}

Table 3. Nelson test used for homogeneity purpose.

\begin{tabular}{|c|c|c|}
\hline \multirow{2}{*}{$\mathrm{N}$} & Valid & 36 \\
\cline { 2 - 3 } & Missing & 0 \\
\hline Mean & 13.55556 \\
\hline \multicolumn{2}{|c|}{ Std. Deviation } & 3.48625 \\
\hline Variance & 12.15397 \\
\hline
\end{tabular}


Table 4. Listening modality (Immediate post-test).

\begin{tabular}{|c|c|c|}
\hline \multirow{2}{*}{$\mathrm{N}$} & Valid & 9 \\
\hline & Missing & 0 \\
\hline \multicolumn{2}{|c|}{ Mean } & 17.22222 \\
\hline \multicolumn{2}{|c|}{ Std. Deviation } & 1.56347 \\
\hline \multicolumn{2}{|c|}{ Variance } & 2.44444 \\
\hline
\end{tabular}

Table 5. Reading modality (Immediate post-test).

\begin{tabular}{|c|c|c|}
\hline \multirow{2}{*}{$\mathrm{N}$} & Valid & 9 \\
\hline & Missing & 0 \\
\hline \multicolumn{2}{|c|}{ Mean } & 18.83333 \\
\hline \multicolumn{2}{|c|}{ Std. Deviation } & 0.93541 \\
\hline \multicolumn{2}{|c|}{ Variance } & 0.875 \\
\hline
\end{tabular}

As displayed in Table 4 and 5, the mean score for the groups that received Listening input is $(M=17.222)$, and the mean score for the group that received Reading is $(M=18.8333)$. Therefore, students who received Reading had the better performance.

\section{2. Delayed Post Test Result}

Table 6. Listening modality (Delayed post-test).

\begin{tabular}{|c|c|c|}
\hline \multirow{2}{*}{$\mathrm{N}$} & Valid & 9 \\
\hline & Missing & 0 \\
\hline \multicolumn{2}{|c|}{ Mean } & 16.33333 \\
\hline \multicolumn{2}{|c|}{ Std. Deviation } & 1.73205 \\
\hline \multicolumn{2}{|c|}{ Variance } & 3 \\
\hline
\end{tabular}


Table 7. Reading modality (Delayed post-test).

\begin{tabular}{|c|c|c|}
\hline \multirow{2}{*}{$\mathrm{N}$} & Valid & 9 \\
\cline { 2 - 3 } & Missing & 0 \\
\hline Mean & 16 \\
\hline \multicolumn{2}{|c|}{ Std. Deviation } & 1.5 \\
\hline Variance & 2.25 \\
\hline
\end{tabular}

As displayed in Table 6 and 7, the mean score for the groups that received Listening input is $(M=16.333)$, and the mean score for the group that receive Reading is $(M=16)$. Hence, there is no significant difference between means of those who received listening and reading inputs.

\section{CONCLUSION}

According to obtained results, reading activity is more effective than listening activity when evaluation of the target group's performance is immediately after the exposure, but in the long run there are no significant differences between groups who received listening instead of the reading tasks. The results of this study are against Vidal (2003) results concerning the priority of listening skill to reading skill, she believed listening is more effective for vocabulary retention. But results of this study emphasize Marcella and Nation (2001) results about high effect of reading for vocabulary retention immediately after the exposure.

\section{References}

[1] Ravandpour A. (2013). Verification of task-induced involvement hypothesis through language modality in incidental vocabulary learning (reading vs. listening modality). The International Journal of Language Learning and Applied Linguistics World, 2; 55-72.

[2] Brown R., Waring R., Donkaewbua S. (2008). Incidental vocabulary acquisition from reading, reading-while- listening and listening to stories. Reading in a Foreign Language, $20 ; 136-163$.

[3] Craik F. I. M., Lockhart R. S. (1972). Levels of processing: A framework for memory research. Journal of verbal learning and verbal behavior, 11; 671-684.

[4] Hulstijn J. H. (1992). Retention of inferred and given word meanings: Experiments in incidental vocabulary learning. In P. J. L. Arnaud \& H. Bejoint (Eds.), vocabulary and applied linguistics (pp. 113-125). London: Macmillan.

[5] Krashen S. (1989). We acquire vocabulary and spelling by reading: Additional evidence for the input hypothesis. Modern Language Journal, 73; 440-464.

[6] Laufer B., Hulstijn J. H. (2001). Incidental vocabulary acquisition in a second language: The construct of task induced involvement. Applied Linguistics, 22; 1-26. 
[7] Liu W., Yun J., Chen N., Tsao S., McCormack S., Wheeler N. (Eds.). (2002). Reading master. Taipei: AMC Publishers.

[8] Martínez-Fernández Ana (2008). Revisiting the Involvement Load Hypothesis: Awareness, Type of Task and Type of Item. In Selected Proceedings of the 2007 Second Language Research Forum, ed. Melissa Bowles, Rebecca Foote, Silvia Perpiñán, and Rakesh Bhatt, 210-228. Somerville, MA: Cascadilla Proceedings Project.

[9] Nelson T. O. (1977). Repetition and depth of processing. Journal of Verbal learning and Verbal Behavior, 16; 151- 171.

[10] Paribakht T. S., Wesche M. (1997). Vocabulary enhancement activities and reading for meaning in second language vocabulary acquisition. Second language vocabulary acquisition: A rationale for pedagogy, 174-200.

[11] Schmitt N. (2008). Review article: instructed second language vocabulary learning. Language Teaching Research, 12(3); 329-363. 


\section{APPENDIX A \\ Nelson Proficiency Test \\ Direction for questions 1-35}

Read the following questions carefully. Then select the one item

$\mathrm{A}, \mathrm{b}, \mathrm{c}$, or $\mathrm{d}$ which is the best answer and mark your sheet.

1. I’m going to spend a few days with some of mine, who live in the north of Scotland.
a. Relatives
b. families
c. neighbors
d. companies

2. The outside the house said "No Parking".
a. Advice
b. signal
c. label
d. notice

3. He has no of winning.
a. Occasion
b. luck
c. opportunity
d. chance

4. These people over there are speaking a language I don`t understand. They must be
a. Foreign
b. strange
c. rare
d. outlandish

5. I didn`t write it. That is not my on the cheque.
a. Mark
b. letter
c. firm
d. signature

6. The actors have to before they appear in front of the strong lights on television.
a. Cover up
b. paint up
c. make up
d. do up

7. It's a difficult problem but we must find the answer
a. By one way or other
c. Somehow or other b. Anyhow or other
d. anyway or other

8. I want immediately. 

a. That this work is made
c. this work made b. That this work is done
d. this work done
9. He`s used to in public.
a. be speaking
b. the speaking
c. speaking
d. speak

10. You can fly to London this evening you don`t mind changing planes in Paris.
a. Provided
b. except
c. unless
d. so far as

11. It's ages him.
a. That I don`t see
c. that I didn`t see b. Ago I saw
d. since I saw

12. He made me
a. Angry
b. be angry
c. to be angry
d. that I got angry

13. Do what you think is right, they say.
a. However
b. whatever
c. whichever
d. for all

14. He arrived late, was annoying.
a. What
b. that
c. which
d. the which

15. His job is yours.
a. The same that
b. as
c. alike
d. similar to

16. He needs a
a. Few days`rest
c. few days' rest
b. Little days` rest
d. little days rest

17. Do you know the repairs?
a. To do
b. how to do
c. to make
d. how to make

18. We usually have fine weather summer. 

a. At
b. on
c. in
d. while

19. Your work has been so we're going to give you a rise in salary.
a. Regular
b. well
c. satisfactory
d. available

20. The weather says it will rain tomorrow.
a. Provision
b. forecast
c. advertisement
d. advice

21. There are a lot of mistakes in this exercise. I'll have to it again with you.
a. Come through
b. go over
c. repass
d. instruct

22. If there are no buses, we 'll have to take a taxi. We must get there
a. Somehow or other
c. somewhere or other
b. On one way or another
d. anyway or other

23. I read, the more I understand.
a. The more
b. so much
c. how much
d. for how much

24. he does his work, I don't mind what time he arrives at the office.
a. So far as
b. so long as
c. in case
d. meanwhile

25 . entering the hall, he found everyone waiting for him.
a. at
b. while
c. on
d. in

26. It's years
a. picture. a. That I don't paint
c. that I didn`t paint
b. Since I painted
d. ago I painted

27. I found the first question
a. To be easy
b. the easy
c. that it was easy
d. easy

28. an empty seat at the back of the bus. 

a. She happened to find
c. she happened to meet
b. It happened her that she found
d. it happened her that she met 29. It was raining, was a pity.
a. What
b. that
c. the which
d. which

30. Your car is mine.
a. The same that
b. as
c. similar to
d. alike

31. I'm going away for a
a. Holiday of a week
c. week holiday
b. Holiday week
d. week`s holiday

32. Why ? It's not very important.
a. To worry
b. worry
c. you are worried
d. you worry

33. I don`t like at me.
a. Them shouting
b. them shout
c. their shout
d. that they shout

34. It often snows January.
a. On
b. in
c. for
d. at

35. That's the best horse in the
a. Career
b. run
c. rate
d. race 


\section{APPENDIX B \\ Reading and Listening Text \\ Keeping a Straight Face}

The last time someone was getting on your nerves, did you let them know they were annoying you, or did you keep a polite - if still hostile - silence? Did you do your best to hide your feelings in order to avoid a conflict or in the hope that the person would shut up and go away? Unfortunately for you if you did, there is some evidence to suggest that you may have paid a high physical and mental price for keeping a straight face. It is well- known that the suppression of strong emotions can affect the heart, but there is also a possibility that it can have a negative effect on the memory. In an experiment not long ago, a group of college students were asked to look at pictures of badly hurt people. Some of them were asked to maintain calm while viewing the pictures. Later, all the students were given a surprise memory test, and the ones asked to hold back their feelings did much worse than the others.

The researchers who did the experiment think that hiding emotions can cause the brain to redirect attention away from some thought processes and weaken the ability to recall things. Brain resources being used to control emotions are not free to aid in other tasks such as thinking clearly and forming memories. Our determination not to show our feelings means, in a way, that we are fooling ourselves about our emotions. This kind of behavior is partly because of the great respect we have for people who are able to keep calm under pressure. A poker face is seen as a sign of strength and of being in control. In all likelihood, people whose outer calm hides an inner storm will have a harder time remembering things. The researchers suggest that we would do better to consider an unpleasant circumstance as a challenge and look for ways to solve it - instead of just gritting our teeth and enduring it in silence.

After reading the article, choose the correct answer to each of the following questions.

1. Keeping a straight face. (A) is priceless (B) causes your heart to stop beating $(C)$ hurts your mind and body

(D) Is the best way to avoid conflict

2. After looking at the pictures of badly hurt people, the students (A) were too surprised to remember anything (B) were given a surprise test to find out how much their memory was affected (C) were asked to hold back their feelings (D) did worse than those who didn't see the pictures

3. Hiding emotions will . (A) Do harm to the brain (B) lead to poor memory (C) assist in clear thinking (D) lead to undivided attention

4. Keeping calm under pressure (A) Makes one look like a fool (B) is considered foolish behavior (C) makes one feel high (D) is highly respected by others 
5. Which of the following statements is true?

(A) It is certain that people who look calm feel peaceful within. (B) We can improve our mind by seeing an unpleasant circumstance as a challenge to test our abilities. (C) Anyone who wears a poker face will be attacked by a storm. (D) We can solve our emotional problems by gritting our teeth and enduring them in silence.

\section{APPENDIX C}

Immediate Posttest Class: No: Name: Score:

Please write down the Persian translation or English explanation for each of the following English words and check on the words that you have known before the test.

\begin{tabular}{|l|l|l|}
\hline 1. annoy & & \\
\hline 2.hostile & & \\
\hline 3.conflict & & \\
\hline 4.unfortunately & & \\
\hline 5.suppression & & \\
\hline 6.maintain & & \\
\hline 7.determination & & \\
\hline 8.circumstance & & \\
\hline 9.grit & & \\
\hline 10.endure & & \\
\hline
\end{tabular}




\section{APPENDIX D}

Delayed Posttest Class: No: Name: Score:

Please write down the Chinese translation or English explanation for each of the following English words and check on the words that you have known before the test

\begin{tabular}{|l|l|l|}
\hline 1. conflict & & \\
\hline 2. grit & & \\
\hline 3. circumstance & & \\
\hline 4. endure & & \\
\hline 5. annoy & & \\
\hline 6. unfortunately & & \\
\hline 7. hostile & & \\
\hline 8. supprssion & & \\
\hline 9. determination & & \\
\hline 10. maintain & & \\
\hline
\end{tabular}

\section{APPENDIX E}

Class: No: Name:

\section{Keeping a Straight Face}

The last time someone was getting on your nerves, did you let them know they were you, or did you keep a polite-if still - silence? Did you do your best to hide your feelings in order to avoid a or in the hope that the person would shut up and go away? for you if you did, there is some evidence to suggest that you may have paid a high physical and mental price for keeping a straight face. It is well- known that the of strong emotions can affect the heart, but there is also a possibility that it can have a negative effect on the memory. In an experiment not long ago, a group of college students were asked to look at pictures of badly hurt people. Some of them were asked to calm while viewing the pictures. Later, all the students were given a surprise memory test, and the ones asked to hold back their feelings did much worse than the others.

The researchers who did the experiment think that hiding emotions can cause the brain to redirect attention away from some thought processes and weaken the ability to recall things. Brain resources being used to control emotions are not free to aid in other tasks such as thinking clearly and forming memories. Our not to show our feelings means, in a way, that we are fooling ourselves about our emotions. This kind of behavior is partly because of the 
great respect we have for people who are able to keep calm under pressure. A poker face is seen as a sign of strength and of being in control. In all likelihood, people whose outer calm hides an inner storm will have a harder time remembering things. The researchers suggest that we would do better to consider an unpleasant as a challenge and look for ways to solve it - instead of just our teeth and it in silence.

annoy (v.): to cause (someone) trouble;

hostile (adj.): unfriendly; \$ \% \& '

conflict (n.): argument;

unfortunately (adv.): by bad luck;

suppression (n.): the act of putting down by force;

maintain (v.): to keep as before;

determination (n.): a firm decision in the mind;

circumstance (n.): situation;

grit (v.): to cause (as one's teeth) to rub together;

endure (v.): to bear 